\title{
Para uma discussão do lugar utópico: a pasárgada bandeiriana habitada por cabo-verdianos e portugueses
}

\author{
Tania Martuscelli \\ (Yale University)
}

\begin{abstract}
RESUMO
Ao comparar alguns aspectos do modernismo brasileiro com o movimento da Claridade em Cabo Verde, é possível reconhecer um traço comum no que concerne a definição de uma identidade enquanto nação, em contraponto com a identidade "portuguesa" que tinha sido imposta nos países-colônias. De fato, o modernismo brasileiro é visto como modelo para seu "irmão", Cabo Verde, devido a aspectos de regionalismo, de nacionalismo e, até certo ponto, de "xenofobia", principalmente em relação a Portugal, o "pai". Eduardo Lourenço, em seu livro A Nau de Ícaro seguido de Imagem e Miragem da Lusofonia (Lisboa: Gradiva,1999), afirma com uma análise psicoanalítica que o Brasil sobreviveria culturalmente somente depois de "matar" o pai: "Para o discurso cultural brasileiro, Portugal existe pouco ou nada, mas, se existe, é apreendido como pai colonizador que o Brasil teve de matar para poder existir"'(150). O mesmo poderia ser referido para Cabo Verde, com a diferença de que este era ainda colônia portuguesa na primeira metade do século XX e, portanto, o processo de "matar" o pai teria de ser feito num âmbito outro, que não o psicoanalítico... O uso da imagética do famoso poema de Manuel Bandeira, "Vou-me embora pra Pasárgada", possibilitaria poetas cabo-verdianos como Jorge Barbosa e Osvaldo Alcântara a proclamar sua liberdade, a exemplo do poeta brasileiro. Este estudo enfoca a relação transcultural e transliterária entre o modernismo brasileiro, o movimento da Claridade na literatura cabo-verdiana e também a "resposta" portuguesa, presente na revista Távola Redonda.
\end{abstract}

PALAVRAS-CHAVE: Pasárgada de Manuel Bandeira, Claridade cabo-verdiana, Neo-Realismo português.

\begin{abstract}
If one contrasts some aspects of Brazilian Modernism and the Capeverdean Claridade, a common thread that defines their identity as nation, and as a counterpart to an imposed identity based on their historic past as colonies of Portugal can be found. Indeed, Brazilian Modernist movement is seen as a model by its "brother-country", Cape Verde, due to its aspects of regionalism, nationalism, and to a certain stand to its "xenophobic" aspect regarding mostly Portugal, the "father-land". Eduardo Lourenço in his book, A Nau de Ícaro seguido de Imagem e Miragem da Lusofonia (Lisboa: Gradiva,1999), states in a pyscoanalytic critique that Brazil would culturally survive only after "killing" its father: "Para o discurso cultural brasileiro, Portugal existe pouco ou nada, mas, se existe, é apreendido como pai colonizador que o Brasil teve de matar para poder existir"(150). The same would apply to Cape Verde, with the difference that it was still a colony in the first half of the 20th century, and, therefore, the "killing" of the father would have to be done on a level other than psychological... The use of an imagery of the well-known poem by Manuel Bandeira, "Vou-me embora pra Pasárgada", would then allow Capeverdean poets such as Jorge Barbosa, Osvaldo Alcântara and José Osório de Oliveira to proclaim their "freedom", as did the Brazilian poet. The present study focuses on the cross-cultural and literary relationship between Brazilian Modernism, the Capeverdean literary movement Claridade, and also the Portuguese "answer" to all this, present in the literary journal Távola Redonda.
\end{abstract}

KEY-WORDS: Manuel Bandeira's Pasargada, Capeverdean journal Claridade, Portuguese neorealism. 
Uma das possíveis vias de análise comparativa entre a literatura brasileira e cabo-verdiana é a de desidentificação com o "pai", isto é, Portugal, sobretudo na primeira metade do século XX. Se relacionarmos as literaturas daquelas ex-colônias por via meramente histórica, podemos afirmar que os africanos são tributários de certa literatura brasileira no que toca à questão da (busca por uma) desidentificação com o pai dada a emancipação política do Brasil em 1822. Outro momento influente a ser mencionado é a subsequente faceta modernizante da literatura e da língua no país. Note-se que por "modernizante" não se deve entender a faceta unicamente modernista, haja vista o quid pro quo entre José de Alencar e Pinheiro Chagas em torno da gramática do português brasileiro e europeu, por exemplo. ${ }^{1}$ Tais momentos de criação literária no Brasil acabaram por servir de modelo a ser seguido por autores cabo-verdianos durante o processo de reflexão sobre sua própria condição de colonizados. A necessidade de desidentificação com Portugal, ainda sob o ponto de vista histórico, era, mais que uma relação em crise entre paipadastro e filho-adotivo, um grito de liberdade preso na garganta por tantos anos de subserviência.

Tendo em vista o título de um conjunto de poemas de Osvaldo Alcântara, pseudônimo de Baltasar Lopes, Itinerário de Pasárgada, publicado pela primeira vez na revista Atlântico e posteriormente publicado no livro Cântico da manhã futura, e ainda o título de um livro de Ovídio Martins, Gritarei, berrarei, matarei: não vou para Pasárgada, não fica difícil referir-se ao talvez mais célebre poema de Manuel Bandeira, "Vou-me embora pra Pasárgada", publicado em 1930 no livro Libertinagem. Note-se ainda que a imagética do mito pasargadiano é retomada em sua "biografia literária", no Itinerário de Pasárgada, e mais tarde, em Mafuá do Malungo de 1949, no poema "Saudades do Rio antigo". A partir destes exemplos, permitimo-nos tratar da referida desidentificação com o pai por via poética e não mais (ou somente) por via histórica. Ademais do conteúdo temático e ideologizante da Pasárgada de Bandeira, sublinhe-se a influência poética de um brasileiro em terras africanas.

Em Osvaldo Alcântara, a influência bandeiriana se dá por um viés parodístico. O termo paródia, neste caso, deve ser assumido pela definição de Hutcheon, como "a suggestion of an accord or intimacy instead of a contrast" (Hutcheon, 1985, p. 32). Por outro lado, para Ovídio Martins, a conotação do lugar pasargadiano é rechaçada: o poeta se recusa a compactuar com a ideia de um "vou-me-emborismo", como já definiu Mário de Andrade, e propõe-se a encarar a realidade de frente, apesar de consciente de sua "prisão" - termo que Sérgio Buarque de Holanda utiliza na introdução ao livro de Bandeira, quando analisa o poema em questão. Para Sérgio Buarque, a "Pasárgada é, ao contrário [da ideia de vou-me-emborismo], a própria vida cotidiana e corrente idealizada de longe; a vida vista de dentro de uma prisão ou de um convento." (Bandeira, 1983, p. 20). O poeta cabo-verdiano anseia por liberdade e parece estar disposto a lutar por ela, mesmo que seja por meio de "berros". Sendo assim, a imagética pasargadiana nos dois poetas africanos pode ser encarada de modo dicotômico, mas não menos influente, uma vez que marca presença de maneira bastante contundente na obra de cada um.

Mencione-se ainda a referência feita ao Brasil no primeiro número da revista Claridade, de março de 1936. Num artigo de José Osório de Oliveira, intitulado "Palavras sobre Cabo Verde para serem lidas no Brasil", a situação socioeconômica e cultural cabo-verdiana é comparada com a situação do nordeste sertanejo brasileiro: 
As afinidades existentes entre Cabo Verde e os estados do Nordeste do Brasil predispunham os caboverdianos para compreender, sentir e amar a nova literatura brasileira. Encontrando exemplos a seguir na poesia e nos romances modernos do Brasil, sentindo-se apoiados na análise do seu caso, pelos novos ensaístas brasileiros, os caboverdianos descobriram o seu caminho. (...) Que os brasileiros a recebam [a revista] como se irmãos seus e subscrevessem, porque como irmãos os consideram os caboverdianos. E que nós portugueses do Continente, saibamos ver nesse entendimento de brasileiros e de caboverdianos a melhor prova de universalidade da nossa acção espiritual, nossa glória eterna. (Oliveira, 1936, s/ p.)

Assinale-se a assunção do caráter de união das duas nações "irmãs", filhas de um mesmo pai (Portugal) e, desse modo, de mesma verve identitária. Verve identitária essa que, como escreve o autor, passa a ser mais brasileira do que propriamente portuguesa, dadas as afinidades históricas e, ainda, de caráter geográfico-sociológico. Entretanto, o articulista, português, deixa entrever sua postura colonizadora ao afirmar que a união fraterna entre Brasil e Cabo Verde nada mais é do que fruto da "acção espiritual" e "glória eterna" portuguesas.

$\mathrm{Na}$ esteira do argumento de Oliveira, e para que o círculo da relação entre "pai" e "filhos" se complete, cabe ainda discorrer sobre o papel representado por Portugal nesse processo. Eduardo Lourenço interessantemente faz notar que a existência cultural do Brasil se deu quando este "matou" o pai, isto é, Portugal, o que, no entanto, não ocorreu de maneira inversa: o Brasil, para os portugueses, nunca morreu. E, daí, a facilidade de aderência ou assimilação literária e cultural: "Para nós, Portugueses, o Brasil é o país-irmão, designação que nos envaidece, naturalmente, mas que, no fundo, tem por objectivo esconder a relação de origem que os Brasileiros não estão interessados em evocar" (Lourenço, 1999, p. 148).

Pode-se tentar definir, desse modo, uma relação de consanguinidade literária que seja - entre os três países de maneira a torná-los irmãos, ou ainda, em certo aspecto, iguais. Entretanto, é importante referir-se ainda ao fato de Lourenço reclamar uma maior atenção por parte dos brasileiros quando referencia questões de língua e identidade cultural. Eduardo Lourenço afirma que Portugal é um pai mal amado ou ignorado: “(...) [nós] em momentos de profundo ressentimento de imaginários pais mal amados ou ignorados, cedemos à tentação de nos enervar com a desatenção brasileira a nosso respeito" (Lourenço, 1999, p. 141). Mais adiante, ao sublinhar uma relação de consanguinidade, similar à que se referiu acima, reclama ainda uma maior atenção ao papel marcante, de base, representado pelos portugueses: "Portugal, 'raiz' do Brasil, seria mais correcto dizer 'sangue' do Brasil, desapareceu, por assim dizer, no fabuloso estuário do 'sangue outro', da 'memória outra', do 'sonho outro' que estrutura hoje, simultaneamente, a vida real e a vida simbólica brasileira." (Lourenço, 1999, p. 157) Tendo "desaparecido", é possível pensar numa relação mais direta entre Brasil e Cabo Verde, por exemplo, relação essa de influência literária, sem passar pelo filtro (ou censura) do pai, e ainda, ao menos sob o ponto de vista do Brasil se se aceita o argumento de Lourenço, sem dar atenção àquela "acção espiritual" ou "glória" portuguesa referida por José Osório de Oliveira, aquando do primeiro número da revista Claridade.

O poema de Manuel Bandeira, "Vou-me embora pra Pasárgada", como explica o poeta no Itinerário de Pasárgada, refere-se a um lugar "onde podemos viver pelo sonho o que a vida madrasta não nos quis dar.”(Bandeira, 
1983, p. 80) Lá, o poeta é "amigo do rei” e pode viver de regalias: "Lá tenho a mulher que eu quero/ $\mathrm{Na}$ cama que escolherei"; além de reviver nostalgicamente a infância: "E como farei ginástica/Andarei de bicicleta/(...)/ Mando chamar a mãe d'água/Pra me contar as histórias/Que no tempo de eu menino/Rosa vinha me contar". Por certo que este lugar utópico em que vive em liberdade (física e moral) é um paraíso também em termos sociais, ademais do prazer pessoal do poeta: "Em Pasárgada tem tudo/É outra civilização/Tem um processo seguro/De impedir a concepção/Tem telefone automático/Tem alcalóide à vontade/Tem prostitutas bonitas/para a gente namorar"'Bandeira, 1983, p. 222).

A Pasárgada de Osvaldo Alcântara de igual modo parece funcionar como o "lugar utópico", ou ainda, o "lugar de redenção" dos poetas, que são "irmãos de Cristo" (Alcântara, 1991, p. 124). O poeta escreve cinco poemas sob o título geral de Itinerário de Pasárgada e publica-os em 1946 na revista lusobrasileira Atlântico. ${ }^{2}$ A concepção dos textos evidentemente se baseia no poema original de Bandeira. O Rei "concede mãos aos homens/para poderem ser cidadãos de Pasárgada./Dá-lhes o martelo e a marreta das catedrais,/para que a Poesia nasça das suas mãos!” A redenção cabo-verdiana, ao que parece, se dá pela poesia de caráter social, ou seja, engajada.

Vai-se constituindo desse modo uma "nova" Pasárgada - agora para os cabo-verdianos, mas não para os surdos, que não ouviram o chamado (um "Grito do Ipiranga"?) e que não foram "à pedreira/arrancar uma pedra para Pasárgada": "Quem tenha ouvidos e oiça, que vá", como escreve o poeta em "Passaporte para Pasárgada", primeiro poema do Itinerário (Alcântara, 1991, p. 115) - Estes últimos versos podem remeter o leitor à imagem de uma "ação social", ou de "revolução", na qual Pasárgada parece ser "construída" por homens-poetas que sonham um mundo melhor.

O segundo poema do itinerário, "Evangelho Segundo o Rei de Pasárgada", inicia-se com versos presentes no poema brasileiro, que funcionam como um "refrão", sem, no entanto, seguirem um ritmo regular: "Em Pasárgada tem tudo,/lá é outra civilização". Ademais deste recurso, o sujeito lírico cabo-verdiano parece se consubstanciar num outro sujeito presente no poema de Bandeira, uma vez que toma atitudes que, de algum modo, coincidem com as do "imigrante brasileiro". Ele quer ouvir o Rei e adormecer, como quando era criança: "Quero ouvir a tua palavra e só a tua palavra;/para que adormeça como quando era pequenino/e meu avô me contava a história do rapazinho que venceu aquele que chegou à casa da Mãe do Vento,/e me dava a moeda de prata para comprar a máscara de papelão", como escreve no poema intitulado, "Dos humildes é o Reino de Pasárgada" (Alcântara, 1991, p. 121). Note-se que os elementos constitutivos do poema, tais como a infância, o contar histórias e mesmo a "Mãe do Vento" (que no poema de Bandeira é "mãe d'água") são evidentemente parodísticos.

A intertextualidade parece se dar também no âmbito de outros poemas de Bandeira, como é o caso de "Evocação do Recife", que trata da lembrança de uma infância inocente, de brincadeiras na rua, quando toda a vizinhança saía para conversar. Alcântara parece transpor essa realidade recifense à sua terra natal, ou, ainda, transpõe a realidade poética de Bandeira à sua própria quando escreve (ainda no âmbito da Pasárgada): "Cavalinhos de Nosso Senhor correm no céu;/a vizinha acalenta o sono do filho rezingão;/Tói Mulato foge a bordo de um vapor;/o comerciante tirou a menina de casa;/os mocinhos da minha rua cantam:/indo eu, indo eu,/a caminho de Viseu..."(Alcântara, 1991, p. 117).

Note-se que a conhecida cantiga popular portuguesa, que substitui a 
cantiga brasileira "Roseira dá-me uma rosa / Craveiro dá-me um botão", presente no poema original (Bandeira, 1983, p. 212), alude à cidade localizada ao centro de Portugal, onde vive o amor do cantor ("indo eu, indo eu/a caminho de Viseu/encontrei o meu amor/ai, Jesus, que lá vou eu"). A Viseu do poeta pode tanto estar concatenada com a imagética da Pasárgada (pois lá está o amor que o cantor encontrou), como também pode se referir à influência paterna de Portugal. Neste segundo caso, cabe retomar o argumento de "consanguinidade" e afirmar que, enquanto a postura poética de desidentificação com o pai se dá por via do imaginário de um "ex-colonizado" - o Brasil pelas mãos de Manuel Bandeira -, a atual postura (de colonizado, que é a do poeta cabo-verdiano) é reafirmada com a presença de um sintagma que está diretamente relacionado ao universo cultural do pai. Assinale-se uma vez mais a afirmação de Lourenço acerca do sangue paterno desaparecido nas veias brasileiras, que contudo não se diluíra totalmente - e nem poderia. $\mathrm{O}$ mesmo se passaria no âmbito de Cabo Verde, uma vez que a mão colonizadora de Portugal ainda se fazia pesada em meados dos anos 40.

O itinerário de Alcântara possui ainda um último poema intitulado "Balada dos Companheiros para Pasárgada" (Alcântara, 1991, p. 119). A "balada" confirma a utopia de um "lugar melhor para se viver", além de certa conotação de caráter político verificada já no título por meio do termo "companheiros". Escreve o poeta: "Além é o horizonte.../E está nos teus passos ir até lá e ver a Ilha Prometida,/ para que o teu coração não tenha um limite e uma distância diferente!" (Alcântara, 1991, p. 119). A conotação de bandeira política se faz presente uma vez mais, sendo, aliás, um momento de ultrapassagem da simbologia do poema bandeiriano. A paródia, neste caso, passa a ser um recurso literário ideal para que sua mensagem atinja o alvo pretendido.

Mencione-se também, uma vez que se trata de literatura de caráter político e politizante, além de utópica, o neorrealismo português que, num período de ditadura, assume uma literatura de caráter regionalista, próxima de um modernismo brasileiro. A obra de Manuel Bandeira, por certo regionalismo e crítica social camuflados numa utopia da infância (ou de Pasárgada) interessantemente passa a influenciar também esta literatura no âmbito português. Note-se que a postura neorrealista é de recusa (ou combate) à assunção do papel de Portugal como pai-padrasto, isto é: trata-se de uma corrente literária que se coloca objetivamente contra o sistema político, sob um ponto de vista marcadamente de esquerda. Evidentemente Bandeira não foi o único brasileiro lido pelos neorrealistas. É, inclusive, o gênero do romance o modo de manifestação mais profuso entre aqueles escritores. Mencionem-se autores como Jorge Amado, Guimarães Rosa, Érico Verissimo e Raquel de Queirós como exemplos da influência brasileira na literatura portuguesa.

Joaquim Namorado, num artigo de 1938, relaciona Gorki com o naturalismo francês e com os novos romances brasileiros, afirmando que "a necessidade de realidade gerou um vasto movimento neorrealista que cresce em todos os continentes" (Tchen, 2001, p. 70). Assinale-se que os romances regionalistas brasileiros e os textos cabo-verdianos são considerados por Namorado igualmente neorrealistas ou de caráter regional. Quanto à aproximação de Cabo Verde com Portugal, segundo Elsa Rodrigues dos Santos chegou-se a aventar em Cabo Verde uma coligação com o movimento da Presença, o que no entanto acabou por ser suplantado pelo ideário nacionalista: "Caboverdianizar a literatura era, afinal, o que pretendiam, a semelhança do que acontecera no Brasil, desde 1922, após a Semana de Arte Moderna." (Santos, 1999, p.276). 
Se nos propusermos a cotejar temporalmente o modernismo brasileiro, a literatura claridosa e negritudinista cabo-verdiana e o neo-realismo português, é possível constituir o seguinte quadro: ${ }^{3}$

\begin{tabular}{|c|c|c|c|}
\hline PERÍODOS & $\begin{array}{l}\text { BRASIL } \\
\text { Modernismo }\end{array}$ & $\begin{array}{l}\text { CABO VERDE } \\
\text { Claridade }\end{array}$ & PORTUGAL \\
\hline 10. & 1922 - "Heróico" & & \\
\hline 20. & $\begin{array}{l}1930 \text { - } \\
\text { "Construtivo" }\end{array}$ & & \\
\hline 30. & 1945 - "Apurado" & $\begin{array}{l}\text { de } 1935 \text { até } 1957 \text { - } \\
\text { "Claridoso" }\end{array}$ & $\begin{array}{l}1935 \text { (ou 1937/38) } \\
\text { até } 1960 \text { - } \\
\text { Neorrealismo }\end{array}$ \\
\hline 40. & & $\begin{array}{l}\text { até } 1965 \text { - } \\
\text { "Negritudinista" }\end{array}$ & \\
\hline
\end{tabular}

No caso português, é interessante fazer notar que a aderência neorrealista às questões socioculturais brasileiras, sobretudo por via do regionalismo, acabou por ser criticada mais tarde, em torno dos anos 50, pelo grupo da revista Távola Redonda. A Pasárgada aparece ali também em forma de paródia. Contudo, no caso da Távola, o recurso se presta à burla. No fascículo 9 da revista, publicado em 1950, leem-se as "Notícias de Pasárgada", nas quais se fazem "estudos" socioeconômicos (para além de históricos) comprovando a inviabilidade de imigração para aquele país, e denotando a opinião crítica dos autores em relação ao "mito pasargadiano". Uma das razões da impossibilidade da imigração, por exemplo, seria a falta de desenvolvimento: não se pode ir lá fazer riqueza, para mal dos poetas que se vão refugiar naquelas terras:

"Pasárgada é, em boa verdade, um mito - um mito igualmente deleterio [sic] ao que foi, em seu tempo, o Brasil e a América do Norte. (...) Nas terras de Pasárgada não há, ao que sabemos, possibilidade de realizar fortuna. País fracamente industrializado (...) não oferece, de modo algum, garantias sólidas de resolução dos problemas dos poetas." (Filipe, 1989, p. 5-6)

Num poema de António Manuel Couto Viana lê-se ainda: "O rei mal me conhece - mal-me-quer" (Viana, 1989, p. 5), o que denota que o papel do poeta português (em Pasárgada) é desimportante. Reconhece-se também o paradeiro de Dom Sebastião que, segundo Luiz de Macedo, é o famoso regente do lugar:

\section{“O REI DE PASÁRGADA É DOM SEBASTIÃO! (...)}

Manuel Bandeira (...) [j]á nos tinha dito que havia um Rei em Pasárgada ('lá sou amigo do rei`) mas disse-nos também que esse Rei era D. Sebastião. (...) ('Joana a louca de Espanha/rainha e falsa demente/vem a ser contraparente/da nora que nunca tive ') (...) A nora de Manuel Bandeira, nora que ele nunca teve no mundo do lado de cá, visto que deve ser casada como [sic] um dos filhos que Bandeira teve do lado de lá, essa nora é filha do rei. (...) E nesse caso é bem de ver que, sendo D. Sebastião bisneto de Joana a louca, o termo parente é o único que explica a relação de parentesco.” (Macedo, 1989, p. 7). 
O tom burlesco com que é tratado o "mito" evidencia o rebaixamento da "poética utópica", de modo que a faceta portuguesa (ou anti neorrealista) na "consanguinidade" pasargadiana se dê ao revés. É interessante incluir ainda o texto "Nos arredores de Pasárgada" de David-Mourão Ferreira, que se abre para outra forma de encarar a realidade - o que, aliás, parece bastante revelador acerca do espírito da revista Távola Redonda, que se propunha a "reagir contra algumas tendências da produção poética da época (...) e contra o impuro aproveitamento da poesia para fins sociais." (Rocha, 1985, p. 487) Note-se a utilização de imagens abstratas que ironizam a adoção do mito da Pasárgada, além da questão social da poesia:

(...) frangos còrados no espeto tomaram atitudes de falcões proféticos e berraram, em côro, coisas profundas. A mais singular foi esta: que a poesia não devia ser pessoal como uma escova de dentes. Adoptaram uma escova de dentes colectiva mas, como alguns deles tinham os dentes cariados, espalhou-se uma epidemia.” (Mourão-Ferreira, 1989, p.5)

Tal epidemia de "dentes cariados" pode referir-se ao neorrealismo português, que, nesse sentido, utilizou coletivamente um "mito pasargadiano" de modo tal que tornou-o lugar-comum: todos vão para a Pasárgada, ou, em outras palavras, todos buscam um lugar utópico como fuga do mundo real. Tal crítica pode ser aproximada à imagética presente no título do livro de Ovídio Martins, mencionado anteriormente, que suplanta a simbologia idealista do poema de Bandeira: Gritarei, berrarei, matarei - não vou para Pasárgada.

É curioso notar que o próprio Manuel Bandeira, na mesma época, em 1949, recicla o mito pasargadiano no poema "Saudades do Rio Antigo", do livro Mafuá do Malungo, reforçando a Pasárgada utópica de outros tempos. Escreve o poeta brasileiro: "Vou-me embora pra Pasárgada./(...)/Aqui não sou feliz./A vida está cada vez/Mais cara, e a menor besteira/Nos custa os olhos da cara."(Bandeira, 1983, p. 425) Pode-se inferir que na visão do brasileiro, diferentemente da visão portuguesa ou de Ovídio Martins, por exemplo, o lugar utópico ainda é melhor do que a realidade de seu tempo, ou ainda, ir para Pasárgada é mais conveniente que lutar. No entanto, e neste caso específico, a dicotomia da imagética bandeiriana pode ser retomada para reaproximar a visão do brasileiro com a visão portuguesa da Távola Redonda, uma vez que ambos se recusam a se comprometer com uma postura de engajamento político. Por outro lado, a Pasárgada de Osvaldo Alcântara é o único lugar possível para a luta, pois o mundo real que habita - Cabo Verde enquanto colônia - é sua prisão.

O mesmo lugar-utópico, portanto, pode funcionar de diversos modos. Oásis para um poeta, é lugar de redenção (política) para outro, mas também palco de vencidos na visão daqueles mais apegados à realidade. Independentemente do que representa, a Pasárgada é seguramente um lugar de encontro: dos sonhadores, dos politizados e dos vencidos. É onde filhos e pai vão se enfrentar sem as amarras que a história criou. A Pasárgada, desse modo, é capaz de irmanar os poetas. ${ }^{4}$

\section{NOTAS}

1. Cf. o "Posfácio à $2^{\mathrm{a}}$. Edição de Iracema" em que o autor contesta a crítica de Pinheiro Chagas: "Acusa-nos o Sr. Pinheiro Chagas a nós escritores brasileiros do crime de insurreição contra a gramática da nossa língua comum. Em sua opinião estamos 
possuídos da mania de tornar o brasileiro uma língua diferente do velho português! Que a tendência, não para a formação de uma nova língua, mas para a transformação profunda do idioma de Portugal, existe no Brasil, é fato incontestável. Mas, em vez de atribuir-nos a nós escritores essa revolução filológica, devia o Sr. Pinheiro Chagas, para ser coerente com sua teoria, buscar o gérmen dela e seu fomento no espírito popular; no falar do povo, esse 'ignorante sublime', como lhe chamou." In: Gilberto Mendonça Telles et al (org.), Prefácios de romances brasileiros. Porto Alegre: Acadêmica, 1986. p.95-111.

2. A ordem em que os poemas aparecem no número 3 da revista, em 1946, é diferente da que fora publicada no livro Cântico da manhã futura. A ordem original era (1) "Passarporte para Pasárgada"; (2) "Evangelho Segundo o Rei de Paságarda"; (3) "Dos Humildes é o Reino de Pasárgada"; (4) "Saudade de Pasárgada"; (5) "Balada dos Companheiros para Pasárgada". A ordem presente no livro editado em 1991 é (1); (5); (4); (2), (3). Vai-se manter, por questões temporais, a ordenação de 1946 publicada na revista, apesar de se estar utilizando a edição mais recente de Cântico da manhã futura como textos de consulta.

3. Cf. Afrânio Coutinho, in: Benedita Gouveia Damasceno, Poesia negra no modernismo brasileiro; Pires Laranjeira, Literaturas africanas de expressão portuguesa; e Carlos Reis, O discurso ideológico do neo-realismo português.

4. Este trabalho foi originalmente elaborado para uma comunicação no XVIIIth International Comparative Literature Association, na Universidade Federal do Rio de Janeiro, entre 29 de julho e 5 de agosto de 2007.

\section{REFERÊNCIAS BIBLIOGRÁFICAS}

ALCÂNTARA, Osvaldo. Cântico da manbã futura. Lisboa: ALAC, 1991.

BANDEIRA, Manuel. Poesia completa e prosa. Rio de Janeiro: Nova Aguilar, 1983.

DAMASCENO, Benedita Gouveia. Poesia negra no modernismo brasileiro. Campinas: Pontes, 1998.

HOLANDA, Sérgio Buarque de. "Trajetória de uma poesia". In: Manuel Bandeira, Poesia completa e prosa, Rio de Janeiro: Nova Aguilar, 1983.

HUTCHEON, Linda. A Theory of Parody - the teachings of Twentieth-Century Art Forms. New York: Methuen, 1985.

LOURENÇO, Eduardo. A nau de Ícaro seguido de imagem e miragem da lusofonia. Lisboa: Gradiva, 1999.

MARTINS, Ovídio. Não vou para Pasárgada: gritarei, berrarei, matarei. [Praia, Cabo Verde]: Instituto de Promoção Cultural, 1998.

OLIVEIRA, José Osório de. Palavras sobre Cabo Verde para serem lidas no Brasil. Claridade. São Vicente, no. 1, s.p., mar. 1936.

PIRES LARANJEIRA, José Luís. Literaturas africanas de expressão portuguesa. Lisboa: Universidade Aberta, 1995.

REIS, Carlos. O discurso ideologico do neo-realismo português. Coimbra: Almedina, 1983.

SANTOS, Elsa Rodrigues dos. A literatura cabo-verdiana e o neo-realismo português. Encontro Neo-Realismo. Museu do Neo-Realismo/Câmara Municipal Vila Franca de Xira, p.276-302, 1999.

TCHEN, Adelaide Ginga. A aventura surrealista. Lisboa: Colibri, 2001.

(Recebido para publicação em 06/I I/2008, Aprovado em 09/01/2009) 